\title{
Comparison of Informal Care Time and Costs in Different Age-Related Dementias: A Review
}

\author{
Nadège Costa, ${ }^{1,2,3,4}$ Laura Ferlicoq, ${ }^{3}$ Hélène Derumeaux-Burel, ${ }^{1,2,3}$ Thomas Rapp, ${ }^{5}$ \\ Valérie Garnault, ${ }^{3}$ Sophie Gillette-Guyonnet, ${ }^{1,2,6}$ Sandrine Andrieu, ${ }^{1,2,7}$ Bruno Vellas, ${ }^{1,2,6}$ \\ Michel Lamure, ${ }^{8}$ Alain Grand, ${ }^{1,2,7}$ and Laurent Molinier ${ }^{1,2,3}$ \\ ${ }^{1}$ UMR1027, Inserm, 31073 Toulouse, France \\ ${ }^{2}$ UMR1027, University of Toulouse III, 31073 Toulouse, France \\ ${ }^{3}$ Medical Information Department, University Hospital of Toulouse, 31059 Toulouse, France \\ ${ }^{4}$ Département d'Information Médicale, Hôtel-Dieu Saint-Jacques, 2 rue Viguerie, TSA 80035, 31059 Toulouse Cedex 9, France \\ ${ }^{5}$ LIRAES, University of Paris Descartes, 75005 Paris, France \\ ${ }^{6}$ Department of Geriatric Medicine, University Hospital of Toulouse, Gérontopôle of Toulouse, 31059 Toulouse, France \\ ${ }^{7}$ Department of Epidemiology and Public Health, University Hospital of Toulouse, 31059 Toulouse, France \\ ${ }^{8}$ EDISS, University of Lyon I, 69100 Villeurbanne, France \\ Correspondence should be addressed to Nadège Costa; costa.n@chu-toulouse.fr
}

Received 12 July 2012; Revised 25 October 2012; Accepted 25 October 2012

Academic Editor: Stefan Agewall

Copyright (C) 2013 Nadège Costa et al. This is an open access article distributed under the Creative Commons Attribution License, which permits unrestricted use, distribution, and reproduction in any medium, provided the original work is properly cited.

\begin{abstract}
Objectives. Age-related dementia is a progressive degenerative brain syndrome whose prevalence increases with age. Dementias cause a substantial burden on society and on families who provide informal care. This study aims to review the relevant papers to compare informal care time and costs in different dementias. Methods. A bibliographic search was performed on an international medical literature database (MEDLINE). All studies which assessed the social economic burden of different dementias were selected. Informal care time and costs were analyzed in three care settings by disease stages. Results. 21 studies met our criteria. Mean informal care time was $55.73 \mathrm{~h}$ per week for Alzheimer disease and $15.8 \mathrm{~h}$ per week for Parkinson disease $(P=0.0076)$, and the associated mean annual informal costs were $\$ 17,492$ versus $\$ 3,284$, respectively $(P=0.0393)$. Conclusion. There is a lack of data about informal care time and costs among other dementias than AD or PD. Globally, AD is the most costly in terms of informal care costs than $\mathrm{PD}, \$ 17,492$ versus $\$ 3,284$, respectively.
\end{abstract}

\section{Introduction}

Dementia is a collective name for progressive degenerative brain syndromes which affect memory, thinking, behavior, and emotion. Symptoms may include loss of memory, difficulty in finding the right word or understanding what people are saying, difficulty in performing previously routine tasks, personality, and mood changes [1]. Age-related dementia refers to a group of dementias whose prevalence increases with age. Alzheimer disease (AD), Parkinson disease (PD), vascular dementia (VD), Lewy body dementia (DLB), and frontotemporal dementia (FTD) are the most common agerelated dementias.
Dementia is one of the major causes of disability and dependence among older people worldwide. It is overwhelming not only for the people who suffer from it but also for their caregivers and families. These diseases cause a substantial burden on society and especially on families who are often required to endorse the informal caregiver's role. Informal care can be defined as unpaid care provided to parents or friends who present functional or/and cognitive disability [2]. However, this definition can be discussed and particularly the notion of "unpaid." According to van den Berg et al., informal caregivers may receive some form of payment. They consider being informal care "when the caregiver would not want to care for someone outside of his 
social environment for a similar wage" [3]. Thus, informal care can be defined as "nearly" unpaid care provided to someone inside the social environment of informal caregiver. The burden of informal care can be the point to an early placement in institution which leads to an increase of total costs $[4,5]$.

With the gross of the worldwide life expectancy, dementia will have a more important impact on society and family burden. Currently, the number of people living with dementia worldwide in 2011 is nearly 35.6 million, increasing to 115.4 million by 2050 [6]. The worldwide economic burden associated with these diseases is estimated at US\$ 604 billion. Informal care costs take an important part in the economic burden of dementia. Indeed, Mauskopf and Mucha estimated at 36 to $85 \%$ the part of informal care in total costs of dementia [7]. Nevertheless, no studies have compared the economic burden of informal costs between different age-related dementias as $\mathrm{AD}, \mathrm{PD}, \mathrm{VD}, \mathrm{FTD}$, or DLB.

The aim of this study is to review relevant papers in order to compare informal care time and informal costs in $\mathrm{AD}, \mathrm{PD}$, DLB, FTD, and VD. Informal care time and costs will be analyzed according to severity stages. We focused on data collected at a given point.

\section{Methods}

\subsection{Cost Study}

2.1.1. Age-Related Dementias. Age-related dementias concern patients aged over 60 years and can refer to $A D, P D, V D$ DLB, and FTD.

$\mathrm{AD}$ is a degenerative brain syndrome characterized by a progressive decline in memory, thinking, comprehension, calculation, language, learning capacity, and judgment sufficient to impair personal activities of daily living. It is the 1 st cause of general and degenerative dementia (60-70\%). Diagnosis is made using NINCDS-ADRDA criteria [8].

$\mathrm{PD}$ is a progressive neurodegenerative disorder, which affects movement or the control of movement, including speech and "body language." Diagnosis is made using UKPDRS criteria [9].

VD is a general term describing problems with reasoning, planning, judgment, memory, and other thought processes resulting from an impaired blood flow in brain. It is the 2nd cause of general dementia after AD: 10 to $20 \%$. Diagnosis is made using NINCDS-AIREN criteria [10].

DLB is a progressive degenerative disease or syndrome of the brain. It shares-and sometimes overlaps-symptoms with several diseases, especially $\mathrm{AD}$ and $\mathrm{PD}$. It is the 2nd cause of degenerative dementia after AD (15-25\%). Diagnosis is made using McKeith et al. criteria [11].

FTD is marked by dramatic changes in personality, behavior (loss of inhibition, apathy, social withdrawal, hyperorality ritualistic compulsive behaviors) and some thought processes. FTD leads to immobility and loss of speech and expression. It represents $10 \%$ of general dementia cases [12].

2.1.2. Disease Severity. As informal care time and costs increase with disease severity, this information must be provided [34-36]. Disease severity is usually measured with the Mini-Mental State Examination (MMSE) [37] for AD and VD and with the Hoehn and Yarh criteria (HY) for PD [38]. Severity of AD and VD is often classified into mild, moderate, and severe stages. However in PD, HY criteria are often classified with numbers ranging from 1 to 5 . To be as homogeneous as possible in this paper, levels 1 and 2 of HY criteria were assimilated as mild, level 3 as moderate, level 4 as moderate to severe, and level 5 as severe.

2.1.3. Place of Living. The place of living must be taken into consideration because different cost components may vary depending on whether the patient lives at home or in institution $[39,40]$. Indeed, when patients live in institution, a large share of costs is attributable to direct medical costs while, for patients living at home, a large share of costs is attributable to informal costs (classified as direct nonmedical costs or indirect costs) [41, 42].

2.1.4. Informal Care Time Measurement. Methods for estimating resource consumption vary depending on the available data.

Some methods are well described in the international literature. The diary method which is perceived as the gold standard for the measurement of time used entails respondents that are asked to write down all their activities during a specific period [43-45] because it collects time allocation data in structured way and involves a relatively short recall period. The recall method entails respondents being asked how much time they spent on a list of activities during, for example, the previous day or week.

Various instruments exist to measure informal caregiving time, such as the Caregiver Activity Time Survey (CATS) [46], the Caregiver Activity Survey (CAS) [47], and the Resource Utilization in Dementia (RUD) [48].

Finally, informal care time can be measured for different activities as activity of daily living (ADL), instrumental activity of daily living (IADL), and supervision [48].

In this paper, if informal care time was not available, we divided annual informal cost by unit cost of one hour of informal care. It gave us hours spent on informal care per year. We assume that informal caregivers provided care seven days a week and 48 weeks by year, because respite structures and other informal or formal caregivers can take care of the patients during four weeks by year. If only annual results were available, it is then divided by 48 to obtain weekly hours of informal care.

2.1.5. Informal Care Costing. Informal care plays a substantial role in the total care for people with chronic disease. Several methods are used to value the shadow price of informal care time.

Opportunity cost approach consists to ask the caregiver to identify the opportunities forgone as a result of caregiving [7]. It attempts to place a monetary value on the alternative use of carer time. In assessing the financial opportunity cost, different values are assigned to caring depending on whether the alternative use of time spent caring is paid as employment 
or leisure time forgone. Valuation will depend on the age, education, and previous work experience of the carer. If caregiver is nonworking, informal care time is valued with leisure time, as a percentage of work time usually between $25 \%$ and $33 \%$ [49].

Replacement cost approach values the time spent on caregiving at the labour market price of a close substitute. Informal care time is valued at the wage rate or market price of a professional caregiver [50]. This approach allows the division of informal care into several tasks and thus to value informal care time with different average wages which can be based on the hourly rates for nurse's aides, cleaners, bookkeepers, and social workers [51].

These two methods are the mainly used [52, 53], but other methods as the well-being valuation (WBV) [54], the contingent valuation method (CVM) [55], or the conjoint measurement (CM) [56] are available to value informal care time.

Van den Berg and Ferrer-I-Carbonell present an alternative valuation method in which the costs of providing informal care are valued in terms of loss of well-being suffered by the informal caregiver. This approach consists in a first step to estimate the effect of providing informal care and of income on individual's subjective well-being and in a second time to estimate the necessary income (compensating variation) to maintain the same level of informal caregiver's wellbeing after providing an additional hour of informal care. This compensating variation is taken as the monetary value of informal care [54].

The CVM is capable of deriving the net value per hour of informal caregiving from the perspective of the informal caregiver [55]. CVM is based on the work of Hicks, who developed measures of losses and keeping utility constant [57]. This method is sensitive to the real individual's preferences [55].

The CM method (or conjoint analysis) is a method for the analysis of respondent's preferences over a set of multiattribute alternatives [56]. The situation differs according to some dimensions called attributes. If the price or cost is included as an attribute, it is possible to derive implicit prices or costs for each of the other dimensions. So a monetary value of the good in question can be derived. Conjoint measurement includes both the informal caregiver's opportunity costs of time and the derived (direct) utility and (direct) disutility of providing care [56].

Moreover, informal care costs can be assessed using its percentage in the total cost (TC) of the disease. Total costs included direct medical costs (e.g., institution costs, medications, inpatients, visits etc.), direct nonmedical costs (e.g., rehabilitation, home help, and transportation), and indirect costs (i.e., productivity losses). Usually, informal care costs are classified as direct nonmedical costs if informal caregiver is considered as a proxy of home help or they can be classified as indirect costs if opportunity costs approach is used.

2.1.6. Statistical Analysis. A comparison between dementia's informal care time and costs was realized. Box plots were performed to measure informal care time and cost's dispersions between dementias. Bivariate analyses were performed to compare informal care time and informal costs between dementias. Student's tests were used to compare samples when the sample distribution was normal and variances were equal. Otherwise, nonparametric tests as Wilcoxon test were used. These tests were performed with STATA 12 software.

\subsection{Literature Review}

2.2.1. Study Selection. A bibliographic search was performed on an international medical literature database (MEDLINE). All studies which assessed social economic burden of $\mathrm{AD}$, $\mathrm{PD}, \mathrm{VD}, \mathrm{FTD}$, or DLB were selected. In order to be as exhaustive as possible, five combinations using keywords were employed: (("Societal costs" OR "Informal costs" OR "Cost of illness") AND "Alzheimer disease"); (("Societal costs" OR "Informal costs" OR "Cost of illness") AND "Parkinson disease"); (("Societal costs" OR "Informal costs" OR "Cost of illness") AND "Vascular dementia"); (("Societal costs" OR "Informal costs" OR "Cost of illness") AND "Fronto-temporal dementia”); (("Societal costs" OR "Informal costs" OR “Cost of illness") AND "Dementia with Lewy Body"). This search provided us 851 papers. We kept the 735 papers written in English language. Among them, we selected articles whose title contained "Alzheimer disease" or "Parkinson disease" or "Vascular dementia" or "Frontotemporal dementia" or "Dementia with Lewy Body" or "Dementia" AND "Societal Costs" or "Cost of illness" or "Costs" (447 papers were removed).

All studies assessing informal time and costs on different dementias at a national level were selected. Ninety-two papers were excluded because they did not assess results at a national level. One hundred and seventy abstracts were first selected, and 58 of them underwent a subsequent full paper reading. Among these, 6 papers were removed because they were longitudinal studies and thus analyzed costs and severity evolution and not cost and severity at a given time, so they do not correspond to our objective that was to estimate costs and severity at a given time [58]. Paper selection provided 21 articles. Figure 1 illustrates the literature search and selection process and presents reasons for excluding studies.

2.2.2. Study Review. A systematic review was performed. One author (N. Costa) selected abstracts. Six methodologists read the 58 papers retrieved by the search strategy and reviewed the 21 selected papers.

\section{Results}

Twenty-one studies met our criteria, and their characteristics are summarized in Table 1. Fifteen studies focused on AD, among them, 8 were carried out in Europe [13-20], 4 in North America [21-24], 2 in Asia [25, 26], and 1 in South America [27]. Five studies focused on PD, among them, 3 were carried out in Europe [28-30], 1 in North America [31], and 1 in Asia [32]. One study carried out in Europe focused on VD [33]. No studies were retrieved about informal costs and time of FTD and DLB. In 19 studies, sample size varied from 42 to $948[13-20,22-32]$ and two studies did not specify the 


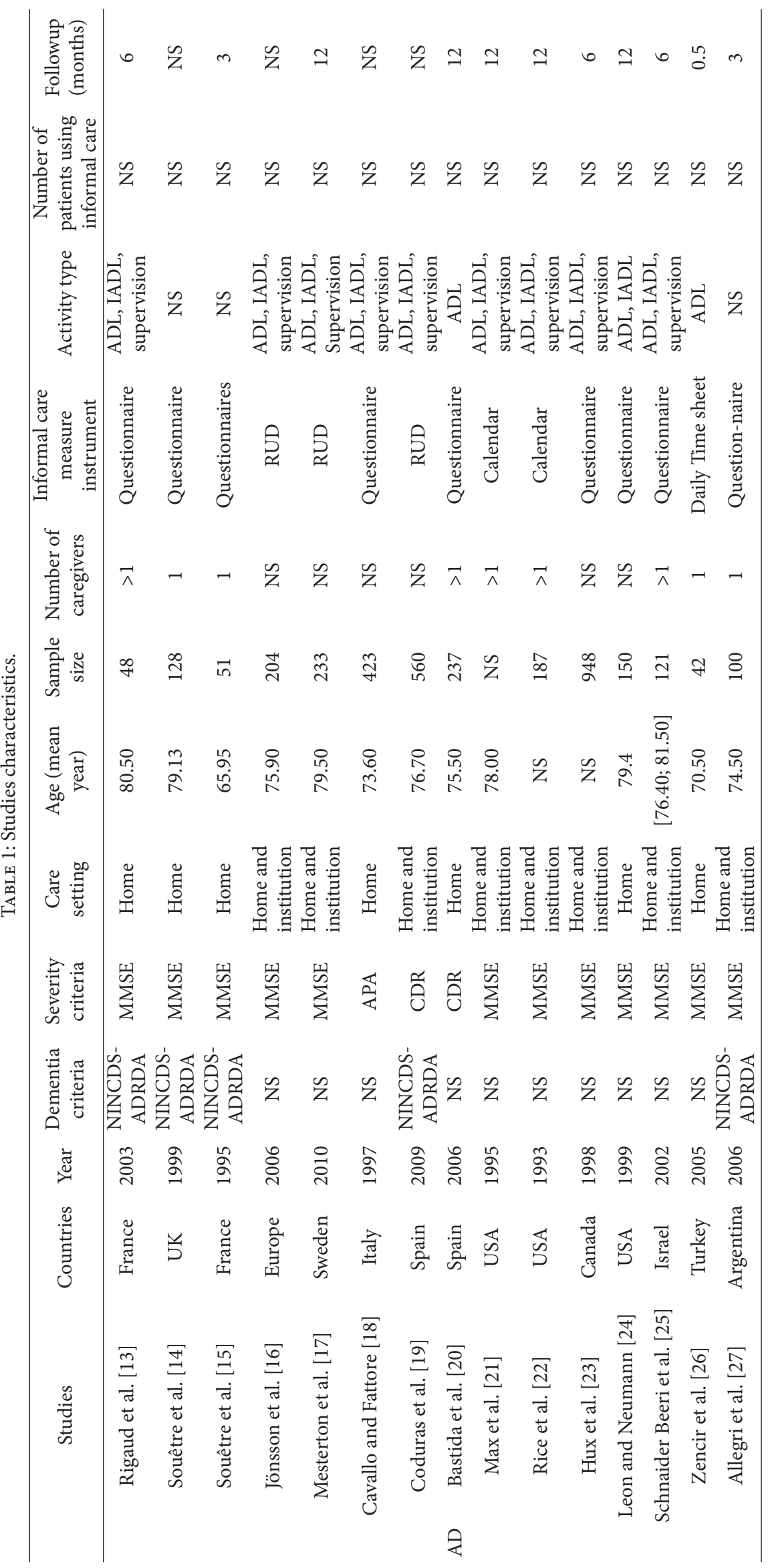




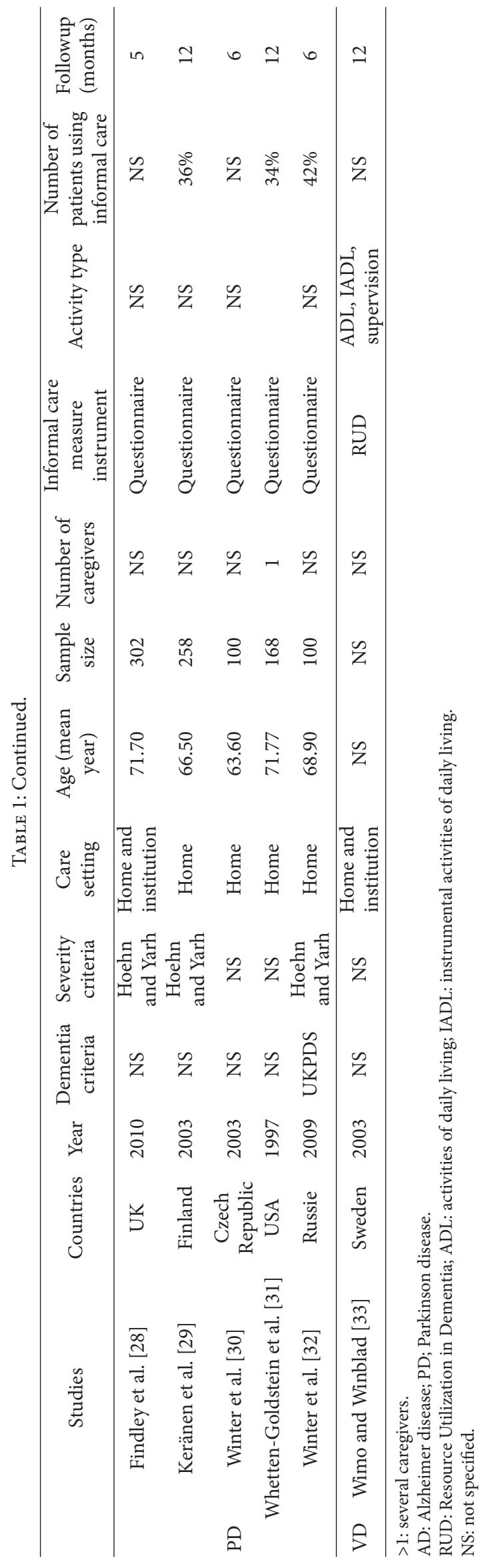




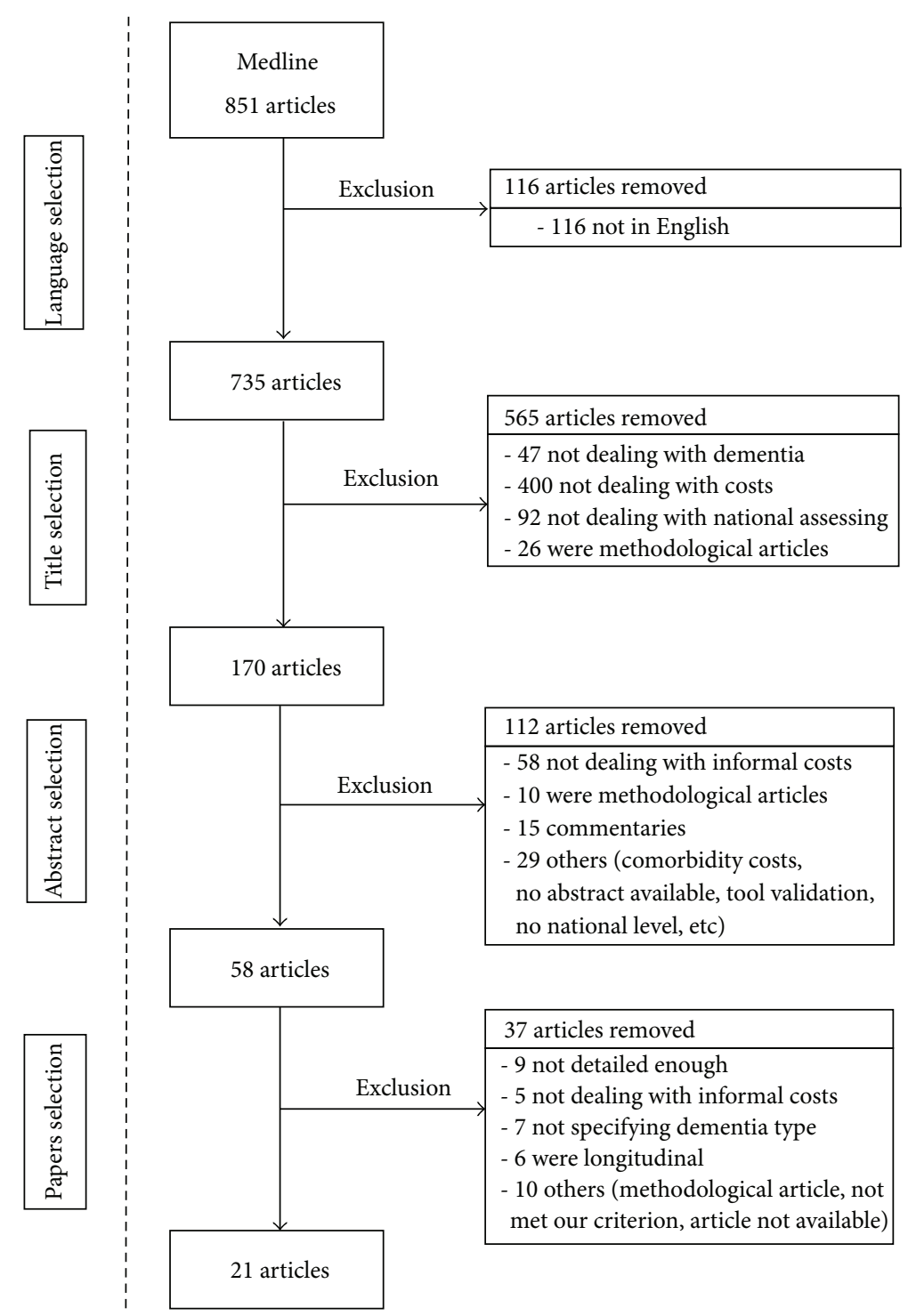

FIGURE 1: Literature search and selection process.

number of patients included $[21,33]$. Studies focused on PD, included patient, between 63.60 and 71.77 years [28-32], and studies focused on AD selected patients between 65.95 and 81.50 years [13-21, 24-27]. Study on VD did not specify the average of patients' age [33].

3.1. Measurement and Costing of Informal Care. Three studies used the diary method to gather time spent on informal care $[21,22,26]$. Among them, two studies recorded data through a calendar and caregivers were asked to report time spent by themselves and other caregivers on caregiving tasks and only regarding Alzheimer disease [21, 22]. This data were collected through 12 monthly interviews. Zencir et al. used daily time shit and asked caregivers to report the time spent on caregiving task on a 15-day period [26].

Sixteen studies used the recall method to gather activity data $[13-20,23-25,27,29-32]$. Among them, 11 studies used ad hoc questionnaires or adapted questionnaires from another studies [13, 14, 18, 20, 23, 25, 27, 29-32], 3 studies used the RUD $[16,17,19]$, and two studies used face to face or telephone interviews $[15,24]$.

Two studies have not defined the method used to gather time spent on caregiving tasks [28, 33].

The recall period was one week for one study [18], one month for 6 studies [13, 17, 22-25], 3 months for 5 studies $[14,15,27,30,32], 6$ months for 2 studies [16, 19], and 12 months for 4 studies [20, 28, 29, 31].

Two studies asked the caregiver about hours spent on caregiving in a typical day $[18,24]$, and 4 studies asked the caregiver about hours spent on caregiving in the last week before the interview $[16,17,19,31]$.

Nine studies used the opportunity cost approach to value informal care time $[14,15,19,23,28-30,32,33]$. Among them, 4 studies valued informal care time as leisure time 
with the disposable income of the caregiver [29, 30, 32, 33]. Four studies valued informal care time as productivity loss with the GDP per capita, the median salary declared by the caregiver, and the hourly wage rate $[15,19,23,28]$. One study valued informal care time according to the caregiver type [14]. The GDP per capita was used to value time spent by retired caregiver and the global average daily salary in Great Britain to value time spent by working caregiver.

Eight studies used the replacement cost approach to value informal care time [13, 18, 20, 24-27]. Two studies used the hourly wage rate for housekeeping [13] and for a nurse working at a public hospital [26]. Two studies used the gross wage for a domestic cleaner [20] and the monthly salary [27]. Three studies valued informal care time according to the different tasks performed by the caregiver [18, 24, 25]. One study used the mean hourly wage rate of 4 at home workers as nurse, housekeeping, bookkeeping, and outdoor maintenance, to value informal care time [25]. One study used the hourly wage of home health aides to value time spent for ADL and the hourly wage of a homemaker to value the time spent for IADL [24]. Another one valued the time spent on care by the hourly wage of a home health and in home labour services and the time spent on supervision with the live-in employees working 55 hours a week [18].

Three studies used the replacement cost and the opportunity cost approaches to value informal care time [21, 22, 31]. Two studies used the replacement cost approach as the mean hourly wage rate of 4 at home workers as nurse, housekeeping, bookkeeping, and outdoor maintenance, to value informal care time, to value time spent by caregiver considered as family and friends and the opportunity cost approach as the mean hourly salary of other visitors than family and friends (e.g., clergy, teachers) [21, 22]. One study used the mean hourly wage rate for formal care declared by the caregiver to value the time spent on caregiving for a patient that used formal and informal care and used the mean hourly wage rate of the caregiver to value time spent for a patient that use only informal care [31].

Two studies used the opportunity cost approach as the average hourly salary of the caregiver to value time spent on caregiving by working caregivers and the contingent valuation or revealed preference analysis to value leisure time lost because of informal care by the retired caregivers $[16,17]$.

3.2. Alzheimer Disease. Among studies focused on AD, 12 [13-15, 18, 20-27] gave informal care time and costs for patients at home (Table 2). Among studies that included only one caregiver, informal care time ranged from $11.59 \mathrm{~h}$ to $47.60 \mathrm{~h}$ per week, and annually informal costs ranged from US $\$ 1,364$ to US $\$ 10,752[14,15,26,27]$. Informal care time ranged from $39.20 \mathrm{~h}$ to $80.00 \mathrm{~h}$ per week among studies that included several caregivers (i.e., >1) [13, 20-22, 25], and the annual informal costs associated ranged from US $\$ 10,700$ to US $\$ 34,517$. Among studies that did not precise the number of caregiver included, informal care time varied from $35.72 \mathrm{~h}$ to $139.30 \mathrm{~h}$ per week, and annual informal costs ranged from US $\$ 7,188$ to US\$34,163 [18, 23, 24]. Globally at home, the number of informal care hours was multiplied by 2.5 between mild $($ mean $=23.26 \mathrm{~h} /$ week) and severe stages (mean $=$ $58.45 \mathrm{~h} /$ week) and the associated annual informal costs were multiplied by 4 , from US $\$ 5,664$ to US $\$ 20,029$ between mild and severe stages. Informal costs accounted for $2.80 \%$ to $84.50 \%$ of total costs.

Five studies estimated informal care time and costs for institutionalized patients [21-23, 25, 27] (Table 3). Among the studies that included several caregivers, informal care time ranged from $8.90 \mathrm{~h}$ to $17.25 \mathrm{~h}$ per week and annually informal costs ranged from US $\$ 2,485$ to US $\$ 5,542[21,22$, $25]$. In the study that included only one caregiver, the amount of informal care time was $3.02 \mathrm{~h}$ per week and the associated informal costs were US\$416 annually [27]. In the study of Hux et al., where the number of caregiver was not defined, the amount of informal care time was $6.30 \mathrm{~h}$ per week and the associated informal costs were US\$1,985 [23]. Globally in institution, the number of informal care hours was multiplied by 2.20 between mild (mean $=4.33 \mathrm{~h} /$ week) and severe stages (mean $=9.49 \mathrm{~h} /$ week $)$ and the associated annual informal costs were multiplied by 2.10 , from US $\$ 2,334$ to US $\$ 4,911$ annually. Informal costs accounted for $2.80 \%$ to $14.60 \%$ of total costs.

Five studies estimated informal care time and costs for patients without distinction between home and institution living $[16,17,19,23,27]$ (Table 4). In the study that included only one caregiver, the amount of informal care time was $13.29 \mathrm{~h}$ per week and the associated informal costs were US $\$ 1,831$ annually [27]. Informal care time ranged from $21.90 \mathrm{~h}$ per week to $66.50 \mathrm{~h}$ per week, and associated informal costs varied from US $\$ 4,428$ to US $\$ 11,251$ annually in the four studies that did not specify the number of caregivers $[16,17,19,23]$. Globally, the number of informal care hours was multiplied by 0.70 between mild (mean $=18.53 \mathrm{~h} /$ week) and severe stages (mean $=27.19 \mathrm{~h} /$ week), and the associated annual informal costs were multiplied by 0.6 , from US $\$ 4,483$ to US\$7,321 annually. Informal care costs accounted for $9.43 \%$ to $52.28 \%$ of total costs.

3.3. Parkinson Disease. Among studies focused on PD, 4 estimated informal care time and costs for patients at home [29-32] (Table 2). Among these, one study included only one caregiver, informal care time was $22.00 \mathrm{~h}$ per week, and associated informal costs were US\$5,386 annually [31]. The other three studies did not specify the number of caregivers involved, and informal care time varied from $10.00 \mathrm{~h}$ to $21.20 \mathrm{~h}$ per week, with associated costs ranging from US $\$ 1,563$ to US $\$ 3,832$ annually $[29,30,32]$. According to studies that estimated precisely informal burden by severity level, the number of informal care hours and costs was 3 times higher in mild stage (hours $=10.00 /$ week; costs $=$ US\$1.132) than in severe stage (hours $=30.80 /$ week; costs $=$ US\$3, 484) [29]. Globally, for patients at home, informal care costs account for $16.00 \%$ to $79.50 \%$.

One study estimated informal care time and costs without defining the place of living [28] (Table 4). The number of informal time was $33.90 \mathrm{~h}$ per week, and informal costs accounted for US\$19,413 annually. Informal care costs accounted for $43.40 \%$ of total costs. 


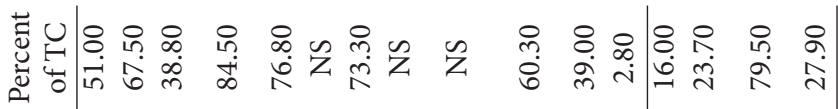

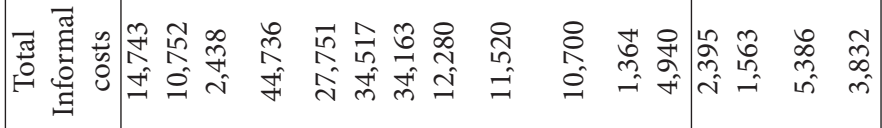

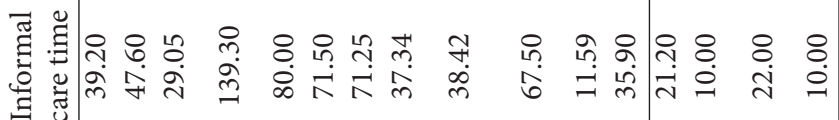

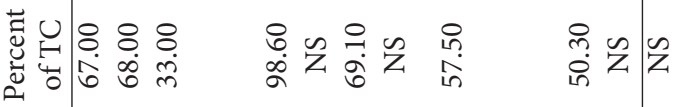

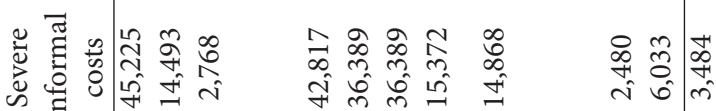

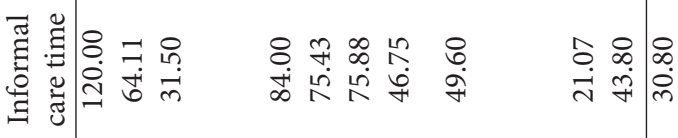

苛

可

至

苋节

苛

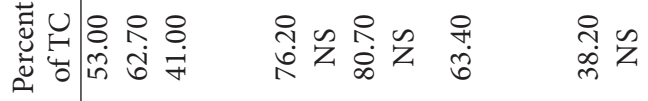

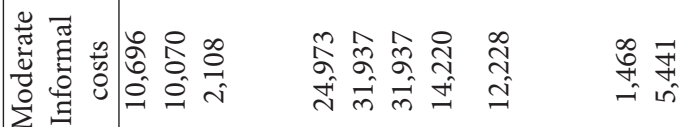

藏节

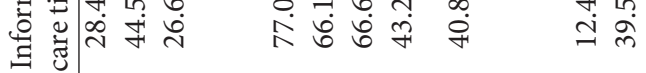

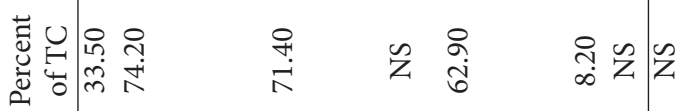

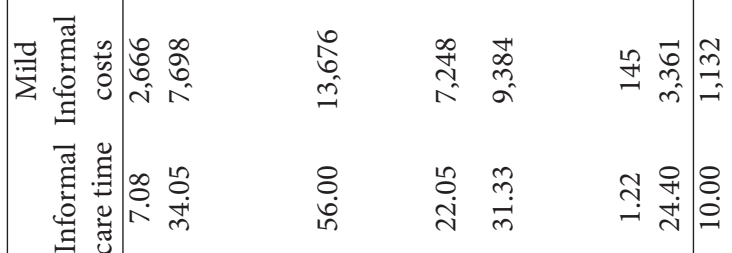

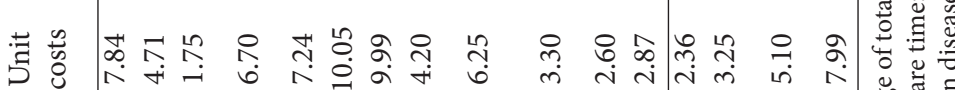

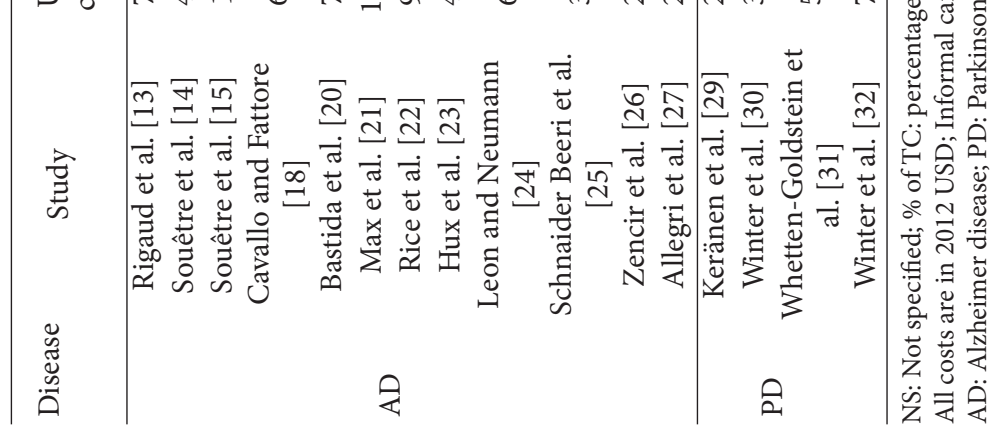




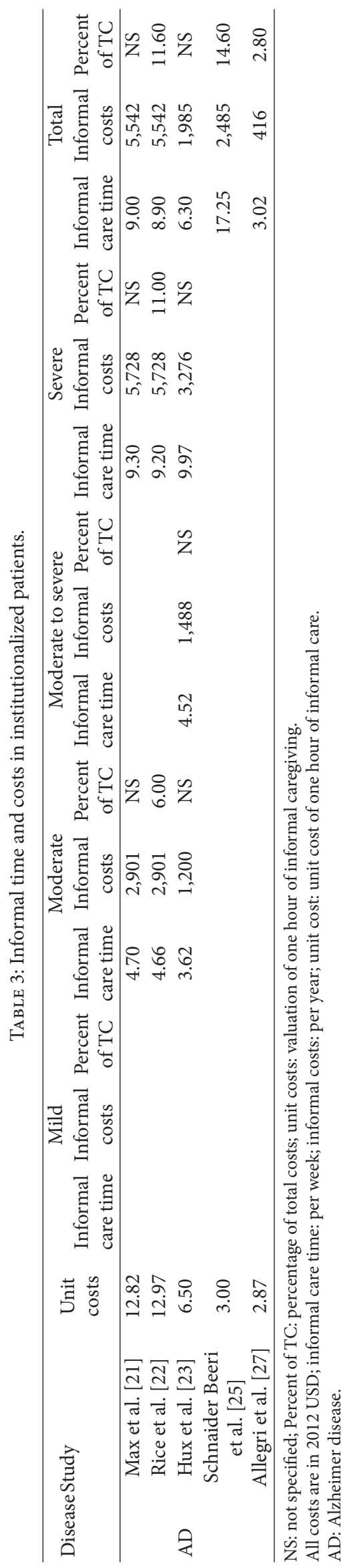




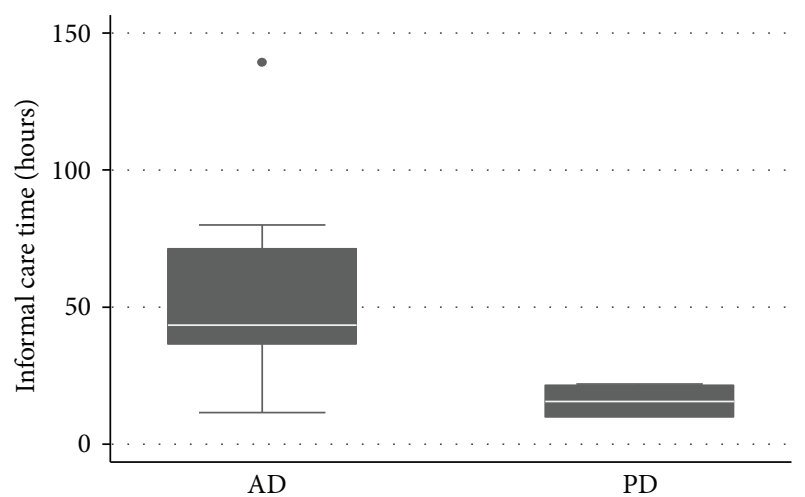

FIGURE 2: Time spent by caregiver (hours/per week) in AD and PD.

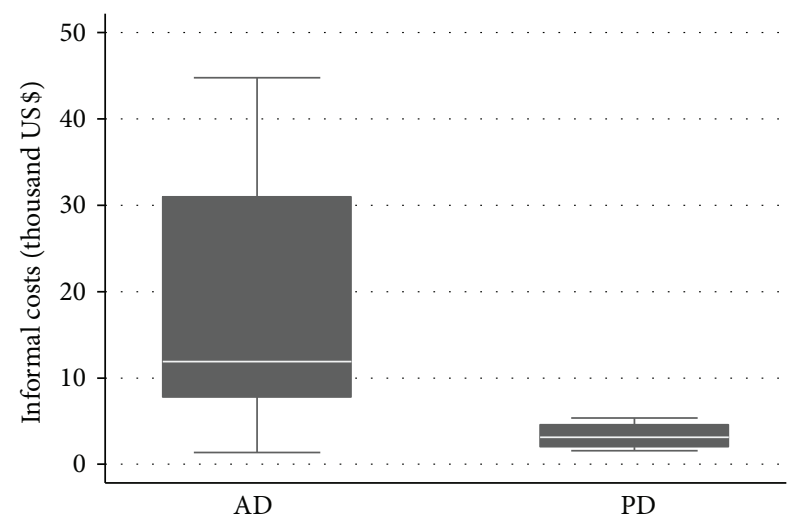

FIGURE 3: Informal costs (US\$) in AD and PD.

3.4. Vascular Dementia. Informal care time, without distinction of place of living, varied from $32.82 \mathrm{~h}$ per week for mild stage to $25.27 \mathrm{~h}$ per week for severe stage [33] (Table 4). Associated informal costs varied from US $\$ 5,782$ to US\$7,508, respectively. Globally for all confounded severity level, informal care time was $39.20 \mathrm{~h}$ per week and informal costs were to US $\$ 8,969$ annually. Informal care costs accounted for $20.80 \%$ of total cost.

\subsection{Comparison of Informal Care Time and Costs between Dementias}

3.5.1. For Patients at Home. For patients at home, informal care time varied from $11.59 \mathrm{~h}$ per week to $80.00 \mathrm{~h}$ per week for $\mathrm{AD}$ and varied from $10.00 \mathrm{~h}$ per week to $22.00 \mathrm{~h}$ per week for $\mathrm{PD}$ (Figure 2). Mean informal care time was $55.73 \pm 33.34 \mathrm{~h}$ per/week for $\mathrm{AD}$ and $15.80 \pm 6.70 \mathrm{~h}$ per week for $\mathrm{PD}(P=$ 0.0076).

For patients at home, informal costs varied from US $\$ 1,364$ to US\$44,736 in AD patients and varied from US $\$ 1,563$ to US\$5,386 annually in PD patients (Figure 3). Annual mean informal costs were US\$17,492 $\pm 14,211$ for AD and US $\$ 3,284 \pm 1,680$ for PD patients $(P=0.0393)$.

3.5.2. Without Distinction of Place of Living. As only one study for PD and one for VD were available, no comparison between informal care time and costs was allowed [26, 31]. However, mean informal care time was $29.19 \mathrm{~h} /$ per week in $\mathrm{AD}, 33.90 \mathrm{~h}$ per week in PD and $39.20 \mathrm{~h}$ per week in VD. The associated costs were US\$6,265, US\$19,413, and US\$8,969, respectively.

\section{Discussion}

We observed results about informal care time and costs only for AD and PD. Globally, informal care time and costs represent a greater burden in $\mathrm{AD}$ than in $\mathrm{PD}(55.73 \mathrm{~h} /$ week versus 15.80 h/week, resp., and US\$17,492 versus US\$3,284 resp.). In this paper, we were unable to compare informal care time and costs between all different major dementias because of the lack of data in VD, FTD, and DLB.

Informal care time and costs varied widely. Commenting on these quantitative results is problematic because significantly different approaches have been adopted to estimate informal costs. Informal caregiving time can be different depending on the number of caregiver involved and according to activities type included in the studies. In this paper, ten studies included several activities type as ADL, IADL, and supervision while three included only time spent on ADL/ IADL and underestimate informal care hours. The difficulty lies also in the measurement of "joint production" which is a concept introduced by Juster and Stafford and which consists in combining informal care with nonmarket activities at the same time (household activities e.g., take advantage of shopping for the patient and for itself at the same time) [43]. On the other hand, it seems to be harder to combine informal care with paid job because employee must be in his/her workplace [59]. To facilitate this measure, when filling in the questionnaire, respondents have to take into account joint production, that is, the possibility to record simultaneous activities [45].

Another problem that is specific to the measurement of informal care is the separation between normal housework that somebody does anyway and "additional housework" that is due to the care demands of the care recipients [45].

In addition, all studies considered only the number of hours of informal care, and they omitted an important dimension which is the timing of care throughout the day and the fluctuations associated. Indeed, the fluctuations increase at specific moments like mealtimes and bedtime. This consideration introduces the notion of "time-bound" which is interested in distinguishing the tasks shiftable over the time-like household and organisation-and the tasks nonshiftable by nature-like personal care, eating, and taking medications. The nonshiftable activities might involve an additional source of opportunity costs because it must be provided at specific moments or times of the day. This account shows the importance of confronting the number of care hours with the type of informal care provided [59].

To value informal care time, if the opportunity cost approach is used, modifications of informal caregiving activities natures will not be taken into account. These changes can be considered if the replacement cost approach is used. A different hourly wage rate can be used according to 


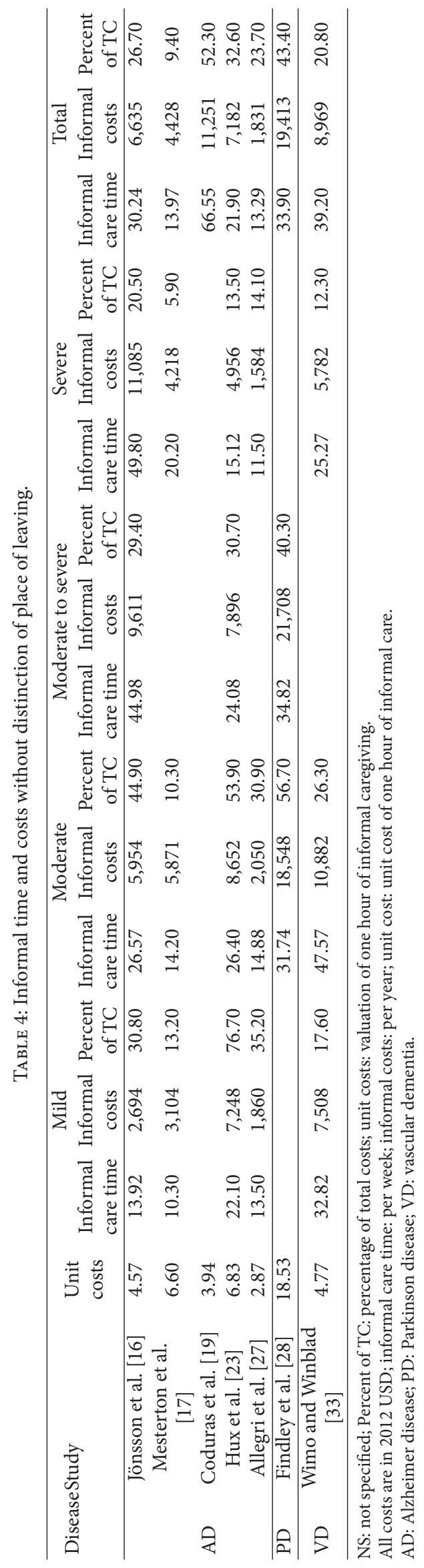


activities performed by the caregiver. For example, time spent by caregiver on ADL tasks can be valued with the wage of home health aides and time spent on IADL tasks can be valued with the wage of a homemaker [60]. Moreover, opportunity cost approach underestimates women, elderly and minorities times who suffer from discrimination in the labour market; in these cases informal care time will be valued with leisure time which is a percentage of work time (usually between 25 and 33\%) [61]. In fact, both methods present limitations. The cost opportunity means giving different values for similar activities depending on who does the work, and the cost replacement means the existence of a perfect replacement specialist on the market. Even if the opportunity cost and the replacement cost approaches are rather insensitive to the heterogeneity and dynamics of informal care, they are the more commonly used because of their simplicity of implementation. In other methods as WB, CM, or CVM, the well-being of the informal caregiver has to be assessed and this information is complicated, long, and expensive to collect in studies [55].

Even if the same approach was used, the hourly wage rate used to value informal time varies widely according to studies. In this paper, the hourly wage of informal caregiver varied from $\$ 4.10$ to $\$ 19.18[14,15,19,23,28-30,32,33]$ if the opportunity cost approach was used and $\$ 2.6$ to $\$ 12.12$ $[13,18,20,22,24-27]$ if the replacement cost was used.

The different dementias described here have different causes. They affect different parts of the brain, which causes a different proportion of functional and cognitive impairment. This explains the different need for informal care in different dementias and thus different informal costs between AD and PD.

No papers were available about informal care time and costs for PD or VD patients in institution. Nevertheless, time spent on informal caregiving for $\mathrm{AD}$ patients was higher at home than in institution. If the place of living is not specified, time spent on informal caregiving and associated costs will be overestimated if only at home patients are included and underestimated if only institutionalized patients are taken into account.

We hypothesized that informal caregiver spent 48 weeks per year and 7 days per week on informal caregiving. We need this information to compare different unit costs and time spent per week on informal caregiving to show results on informal care costs and time in different age-related dementias. This is a strong assumption, but no article was available on the time spent per year on informal caregiving tasks. We took 48 weeks per year because we assume that caregiver could work and have only one month of holidays, so they would work 11 months per year [62]. During these "holidays" informal caregivers can rely on respite structures, other informal or formal caregivers. We took seven days a week because, even if employees work 5 or 6 days a week, we considered that informal caregiver cannot let his/her related alone during the weekend. We are aware that informal care time is different between severity stages, so for the mild stage maybe we overestimate informal care time and for the moderate and severe stages we underestimate informal caregiving time [63].
In the study of van den Berg and Spauwen with the diary method, informal caregivers report that in $9.11 \mathrm{~h}$ per day of informal care they spent $3.42 \mathrm{~h}$ per day for ADL tasks [45]. Based on these results, we can estimate that more than $1 / 3$ of caregiver's time is devoted to tasks like ADL. Being by nature nonshiftable, these activities are more stringent for caregivers with employment. If the formal care covers these kinds of activities, which represent third of the hours of informal care, this would reduce the burden on informal caregivers and could allow the decrease of early institutionalization $[4,5]$. This issue could lead on the one hand to an increase in employment opportunity in personal assistance area and on the other hand to an increase in labour market participation of informal caregivers [59].

Most of the studies reviewed here took a follow-up period that did not exceed one year. The one-year follow-up period is short to assess chronic diseases costs that have an impact more heavily on society as far as the physical or psychological disabilities progress. However, data collection over a long period is difficult so the use of models may compensate this difficulty.

There is a lack of specific criteria to diagnose each dementia described here. Indeed, specific diagnosis criteria are well defined for $\mathrm{AD}$ and $\mathrm{PD}[8,9,37,38]$, and this is not necessarily the case for the other dementias [64]. This would explain the difficulty to build studies on specific dementia that are difficult to diagnose with diagnostic criteria that we currently have.

In this paper, we focused on objective burden (in relation to the time spent on informal caregiving). It is interesting to note that there is a distinction between objective and subjective burdens [65]. The last one refers to different impacts: physical, psychological, emotional and so on. Mental illnesses, like dementia, are particularly impacted by subjective burden. The study of Hastrup et al. has been shown, using Caregiver Strain Index in which mental illnesses are associated with a higher burden compared with somatic diseases. The subjective burden is impacted by the objective burden. Indeed, the number of hours per week spent on informal caregiving had a statistically significant impact on the subjective burden of caregiver. The more the number of informal care hours increases, the more the subjective burden is important. Beyond 50 hours per week, subjective burden is greatly increasing [65]. In this paper of the literature, we did not focus on this type of information. However, informal care provides to caregivers positives aspects [66].

For all these reasons, the results seem difficult to generalize and then limit the scope for international comparison. Economic results are difficult to compare on account of monetary issues, such as fluctuating exchange rates and different purchasing powers of currencies. Domestic characteristics also affect resources consumption and unit costs, including differences in clinical practice and health care system framework.

In our paper, only transversal studies were included. This analysis of informal care time and costs could be completed by wide analysis including all kind of studies (i.e., longitudinal, cost-effectiveness, cost utility). 
Despite its limitations, this paper has the merit of showing that informal care time and costs are insufficiently considered although they play an important role in economic burden to society and families.

\section{Conclusion}

Although PD informal care time and costs are lower than $\mathrm{AD}$ informal care time and costs, both dementias represent a significant economic burden to society. The preoccupation of economists on the burden of the disease joined the policies and caregivers preoccupations. This collective awareness can be a basis for decision-making. An effort should be made by the scientific community to estimate the economic burden of informal care in different dementias. This would provide information to allow a better decision-making about public health priorities in dementias.

\section{References}

[1] Alzheimer's Association Report. Alzheimer's disease facts and figures. 2010.

[2] K. M. Langa, M. E. Chernew, M. U. Kabeto et al., "National estimates of the quantity and cost of informal caregiving for the elderly with dementia," Journal of General Internal Medicine, vol. 16, no. 11, pp. 770-778, 2001.

[3] B. van den Berg, W. B. F. Brouwer, and M. A. Koopmanschap, "Economic valuation of informal care: an overview of methods and applications," The European Journal of Health Economics, vol. 5, no. 1, pp. 36-45, 2004.

[4] H. Verbeek, G. Meyer, H. Leino-Kilpi et al., "A European study investigating patterns of transition from home care towards institutional dementia care: the protocol of a RightTimePlaceCare study," BMC Public Health, vol. 12, article 68, 2012.

[5] R. Hébert, M. F. Dubois, C. Wolfson, L. Chambers, and C. Cohen, "Factors associated with long-term institutionalization of older people with dementia: data from the Canadian study of health and aging," Journals of Gerontology A, vol. 56, no. 11, pp. M693-M699, 2001.

[6] Alzheimer's Disease International, World Alzheimer Report 2010: The Global Economic Impact of Dementia, 2011.

[7] J. Mauskopf and L. Mucha, "A review of the methods used to estimate the cost of Alzheimer's disease in the United States," American Journal of Alzheimer's Disease and other Dementias, vol. 26, no. 4, pp. 298-309, 2011.

[8] G. McKhann, D. Drachman, and M. Folstein, "Clinical diagnosis of Alzheimer's disease: report of the NINCDS-ADRDA work group under the auspices of Department of Health and Human Services Task Force on Alzheimer's disease," Neurology, vol. 34, no. 7, pp. 939-944, 1984.

[9] Gibb and Lees, United Kingdom Parkinson's Disease Society Brain Bank Clinical Diagnosis Criteria, 1988.

[10] G. C. Román, T. K. Tatemichi, T. Erkinjuntti et al., "Vascular dementia: diagnostic criteria for research studies: report of the NINDS-AIREN International Workshop," Neurology, vol. 43, no. 2, pp. 250-260, 1993.

[11] I. G. McKeith, D. Galasko, K. Kosaka et al., "Consensus guidelines for the clinical and pathologic diagnosis of dementia with Lewy bodies (DLB): report of the consortium on DLB international workshop," Neurology, vol. 47, no. 5, pp. 1113-1124, 1996.
[12] The Lund and Manchester Groups, "Clinical and neuropathological criteria for frontotemporal dementia," Journal of Neurology, Neurosurgery \& Psychiatry, vol. 57, no. 4, pp. 416-418, 1994.

[13] A. S. Rigaud, F. Fagnani, C. Bayle, F. Latour, L. Traykov, and F. Forette, "Patients with Alzheimer's disease living at home in France: costs and consequences of the disease," Journal of Geriatric Psychiatry and Neurology, vol. 16, no. 3, pp. 140-145, 2003.

[14] E. Souêtre, R. M. Thwaites, and H. L. Yeardley, "Economic impact of Alzheimer's disease in the United Kingdom: cost of care and disease severity for non-institutionalised patients with Alzheimer's disease," British Journal of Psychiatry, vol. 174, pp. 51-55, 1999.

[15] E. J. Souêtre, W. Qing, I. Vigoureux et al., "Economic analysis of Alzheimer's disease in outpatients: impact of symptom severity," International Psychogeriatrics, vol. 7, no. 1, pp. 115-122, 1995.

[16] L. Jönsson, M. E. Jönhagen, L. Kilander et al., "Determinants of costs of care for patients with Alzheimer's disease," International Journal of Geriatric Psychiatry, vol. 21, no. 5, pp. 449-459, 2006.

[17] J. Mesterton, A. Wimo, A. By, S. Langworth, B. Winblad, and L. Jönsson, "Cross sectional observational study on the societal costs of Alzheimer's disease," Current Alzheimer Research, vol. 7, no. 4, pp. 358-367, 2010.

[18] M. C. Cavallo and G. Fattore, "The economic and social burden of Alzheimer disease on families in the Lombardy Region of Italy," Alzheimer Disease and Associated Disorders, vol. 11, no. 4, pp. 184-190, 1997.

[19] A. Coduras, I. Rabasa, A. Frank et al., "Prospective one-year cost-of-illness study in a cohort of patients with dementia of Alzheimer's disease type in Spain: the ECO study," Journal of Alzheimer's Disease, vol. 19, no. 2, pp. 601-615, 2010.

[20] J. L. Bastida, P. Serrano-Aguilar, L. Perestelo-Perez, and J. OlivaMoreno, "Social-economic costs and quality of life of Alzheimer disease in the Canary Islands, Spain," Neurology, vol. 67, no. 12, pp. 2186-2191, 2006.

[21] W. Max, P. Webber, and P. Fox, “Alzheimer's disease: the unpaid burden of caring," Journal of Aging and Health, vol. 7, no. 2, pp. 179-199, 1995.

[22] D. P. Rice, P. J. Fox, W. Max et al., "The economic burden of Alzheimer's disease care," Health Affairs, vol. 12, no. 2, pp. 164-176, 1993.

[23] M. Hux, B. O’Brien, M. Iskedjian, R. Goeree, M. Gagnon, and S. Gauthier, "Relation between severity of Alzheimer's disease and costs of caring," Canadian Medical Association Journal, vol. 159, no. 5, pp. 457-465, 1998.

[24] J. Leon and P. J. Neumann, “The cost of Alzheimer's disease in managed care: a cross-sectional study," The American Journal of Managed Care, vol. 5, no. 7, pp. 867-877, 1999.

[25] M. Schnaider Beeri, P. Werner, Z. Adar, M. Davidson, and S. Noy, "Economic cost of Alzheimer disease in Israel," Alzheimer Disease and Associated Disorders, vol. 16, no. 2, pp. 73-80, 2002.

[26] M. Zencir, N. Kuzu, G. Beşer, A. Ergin, B. Çatak, and T. Şahiner, "Cost of Alzheimer's disease in a developing country setting," International Journal of Geriatric Psychiatry, vol. 20, no. 7, pp. 616-622, 2005.

[27] R. F. Allegri, J. Butman, R. L. Arizaga et al., "Economic impact of dementia in developing countries: an evaluation of costs of Alzheimer-type dementia in Argentina," International Psychogeriatrics, vol. 19, no. 4, pp. 705-718, 2007. 
[28] L. Findley, E. Wood, J. Lowin, C. Roeder, A. Bergman, and M. Schifflers, "The economic burden of advanced Parkinson's disease: an analysis of a UK patient dataset," Journal of Medical Economics, vol. 14, no. 1, pp. 130-139, 2011.

[29] T. Keränen, S. Kaakkola, K. Sotaniemi et al., "Economic burden and quality of life impairment increase with severity of PD," Parkinsonism \& Related Disorders, vol. 9, no. 3, pp. 163-168, 2003.

[30] Y. Winter, S. Campenhausen, H. Brozova et al., "Costs of Parkinson's disease in Eastern Europe: a Czech cohort study," Parkinsonism \& Related Disorders, vol. 16, no. 1, pp. 51-56, 2010.

[31] K. Whetten-Goldstein, F. Sloan, E. Kulas, T. Cutson, and M. Schenkman, "The burden of Parkinson's disease on society, family, and the individual," Journal of the American Geriatrics Society, vol. 45, no. 7, pp. 844-849, 1997.

[32] Y. Winter, S. Campenhausen, G. Popov et al., "Costs of illness in a Russian cohort of patients with Parkinson's disease," PharmacoEconomics, vol. 27, no. 7, pp. 571-584, 2009.

[33] A. Wimo and B. Winblad, "Societal burden and economics of vascular dementia: preliminary results from a Swedishpopulation-based study," International Psychogeriatrics, vol. 15, no. 1, pp. 251-256, 2003.

[34] W. Quentin, S. G. Riedel-Heller, M. Luppa, A. Rudolph, and H. H. König, "Cost-of-illness studies of dementia: a systematic review focusing on stage dependency of costs," Acta Psychiatrica Scandinavica, vol. 121, no. 4, pp. 243-259, 2010.

[35] J. Mauskopf, J. Racketa, and E. Sherrill, "Alzheimer's disease: the strength of association of costs with different measures of disease severity," The Journal of Nutrition, Health \& Aging, vol. 14, no. 8, pp. 655-663, 2010.

[36] N. Herman, D. Y. Tam, R. Balshaw et al., "The relation between disease severity and cost of caring for patients with Alzheimer disease in Canada," Canadian Journal of Psychiatry, vol. 55, no. 12, pp. 768-775, 2010.

[37] R. M. Crum, J. C. Anthony, S. S. Bassett, and M. F. Folstein, "Population-based norms for the mini-mental state examination by age and educational level," Journal of the American Medical Association, vol. 269, no. 18, pp. 2386-2391, 1993.

[38] M. M. Hoehn and M. D. Yahr, "Parkinsonism: onset, progression and mortality," Neurology, vol. 17, no. 5, pp. 427-442, 1967.

[39] G. W. Small, D. D. McDonnell, R. L. Brooks, and G. Papadopoulos, "The impact of symptom severity on the cost of Alzheimer's disease," Journal of the American Geriatrics Society, vol. 50, no. 2, pp. 321-327, 2002.

[40] C. W. Zhu, N. Scarmeas, R. Torgan et al., "Longitudinal study of effects of patient characteristics on direct costs in Alzheimer disease," Neurology, vol. 67, no. 6, pp. 998-1005, 2006.

[41] K. Érsek, T. Kovács, A. Wimo et al., "Costs of dementia in Hungary," The Journal of Nutrition, Health \& Aging, vol. 14, no. 8, pp. 633-639, 2010.

[42] E. O'Shea and S. O'Reilly, “The economic and social cost of dementia in Ireland," International Journal of Geriatric Psychiatry, vol. 15, no. 3, pp. 208-218, 2000.

[43] F. T. Juster and F. P. Stafford, "The allocation of time: empirical findings, behavioral models, and problems of measurement," Journal of Economic Literature, vol. 29, no. 2, pp. 471-522, 1991.

[44] J. P. Robinson, "The validity and reliability of diaries versus alternative time use measures," in Time, Goods, and Well-Being, F. T. Juster and F. P. Stafford, Eds., Institute for Social Research, The University of Michigan, Ann Arbor, Mich, USA, 1985.
[45] B. van den Berg and P. Spauwen, "Measurement of informal care: an empirical study into the valid measurement of time spent on informal caregiving," Health Economics, vol. 15, no. 5, pp. 447-460, 2006.

[46] E. C. Clipp and M. J. Moore, "Caregiver time use: an outcome measure in clinical trial research on Alzheimer's disease," Clinical Pharmacology and Therapeutics, vol. 58, no. 2, pp. 228-236, 1995.

[47] K. L. Davis, D. B. Marin, R. Kane et al., “The Caregiver Activity Survey (CAS): development and validation of a new measure for caregivers of persons with Alzheimer's disease," International Journal of Geriatric Psychiatry, vol. 12, no. 10, pp. 978-988, 1997.

[48] A. Wimo, L. Jonsson, and A. Zbrozek, “The Resource Utilization in Dementia (RUD) instrument is valid for assessing informal care time in community-living patients with dementia," The Journal of Nutrition, Health \& Aging, vol. 14, no. 8, pp. 685-690, 2010.

[49] E. O'Shea, “The costs of caring for people with dementia and related cognitive impairment," Report 60, National Council on Ageing and Older People, 2000.

[50] B. van den Berg, W. Brouwer, J. van Exel, M. Koopmanschap, G. A. M. van den Bos, and F. Rutten, "Economic valuation of informal care: lessons from the application of the opportunity costs and proxy good methods," Social Science \& Medicine, vol. 62, no. 4, pp. 835-845, 2006.

[51] B. S. Harrow, S. L. Tennstedt, and J. B. McKinlay, "How costly is it to care for disabled elders in a community setting?" Gerontologist, vol. 35, no. 6, pp. 803-813, 1995.

[52] J. Posnett and S. Jan, "Indirect cost in economic evaluation: the opportunity cost of unpaid inputs," Health Economics, vol. 5, no. 1, pp. 13-23, 1996.

[53] M. A. Koopmanschap, N. J. A. van Exel, B. van den Berg, and W. B. F. Brouwer, "An overview of methods and applications to value informal care in economic evaluations of healthcare," PharmacoEconomics, vol. 26, no. 4, pp. 269-280, 2008.

[54] B. van den Berg and A. Ferrer-I-Carbonell, "Monetary valuation of informal care: the well-being valuation method," Health Economics, vol. 16, no. 11, pp. 1227-1244, 2007.

[55] B. van den Berg, W. Brouwer, J. van Exel, and M. Koopmanschap, "Economic valuation of informal care: the contingent valuation method applied to informal caregiving," Health Economics, vol. 14, no. 2, pp. 169-183, 2005.

[56] B. van den Berg, M. Al, W. Brouwer, J. van Exel, and M. Koopmanschap, "Economic valuation of informal care: the conjoint measurement method applied to informal caregiving," Social Science \& Medicine, vol. 61, no. 6, pp. 1342-1355, 2005.

[57] J. R. Hicks, “The foundations of welfare economics," The Economic Journal, vol. 49, no. 196, pp. 696-712, 1939.

[58] N. Zay, Dictionnaire-Manuel de Gérontologie Sociale, Presse de l'université Laval, Quebec, Canada, 1981.

[59] W. Hassink and B. van den Berg, "Time-bound opportunity costs of informal care: consequences for access to professional care, caregiver support, and labour supply estimates," Social Science \& Medicine, vol. 73, no. 10, pp. 1508-1516, 2011.

[60] J. Leon, C. K. Cheng, and P. J. Neumann, "Alzheimer's disease care: costs and potential savings," Health Affairs, vol. 17, no. 6, pp. 206-216, 1998.

[61] J. E. Segel, “Cost-of-Illness studies-A primer," RTI-UNC Center of Excellence in Health Promotion Economics, p.p 1-39, 2006. 
[62] R. Ray and J. Schmitt, "No-vacation nation: a comparison of leave and holiday in OECD countries," European Economic and Employment Policy Brief, no. 3, p. 24, 2007.

[63] C. Bakker, M. E. de Vugt, D. van Vliet et al., "The use of formal and informal care in early onset dementia: results from the NeedYDStudy," American Journal of Geriatric Psychiatry. In press.

[64] V. Hachinski, "Shifts in thinking about dementia," Journal of the American Medical Association, vol. 300, no. 18, pp. 2172-2173, 2008.

[65] L. H. Hastrup, B. van den Berg, and D. Gyrd-Hansen, "Do informal caregivers in mental illness feel more burdened? A comparative study of mental versus somatic illnesses," Scandinavian Journal of Public Health, vol. 39, no. 6, pp. 598-607, 2011.

[66] G. Szmukler, "From family 'burden' to caregiving," The Psychiatrist, vol. 20, pp. 449-451, 1996. 


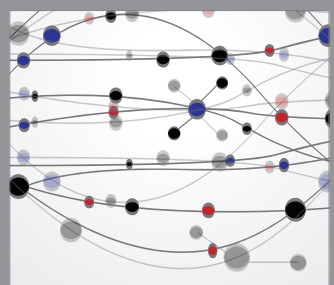

The Scientific World Journal
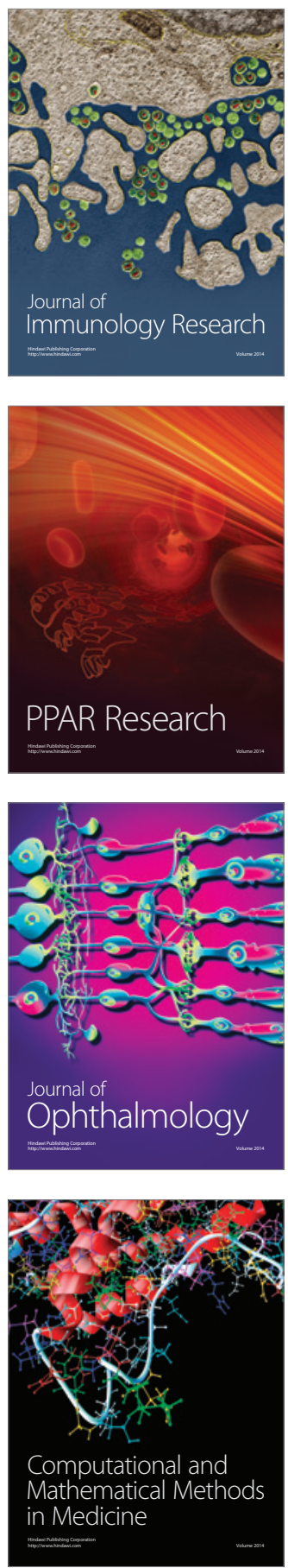

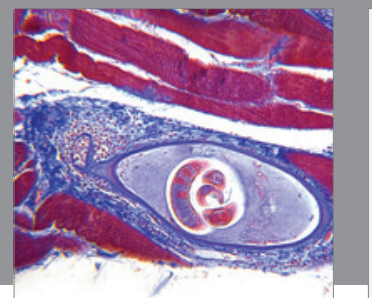

Gastroenterology

Research and Practice
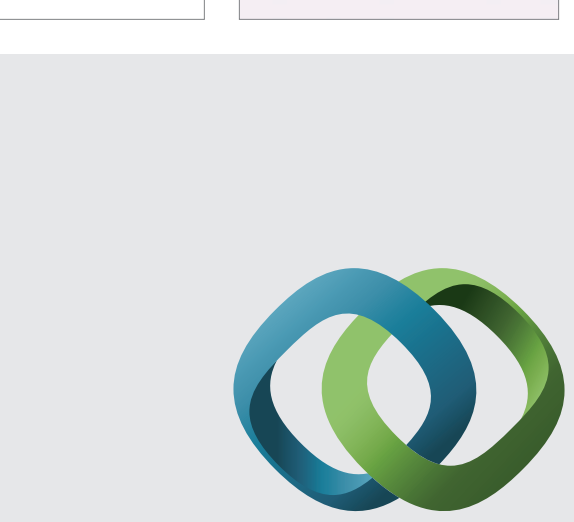

\section{Hindawi}

Submit your manuscripts at

http://www.hindawi.com
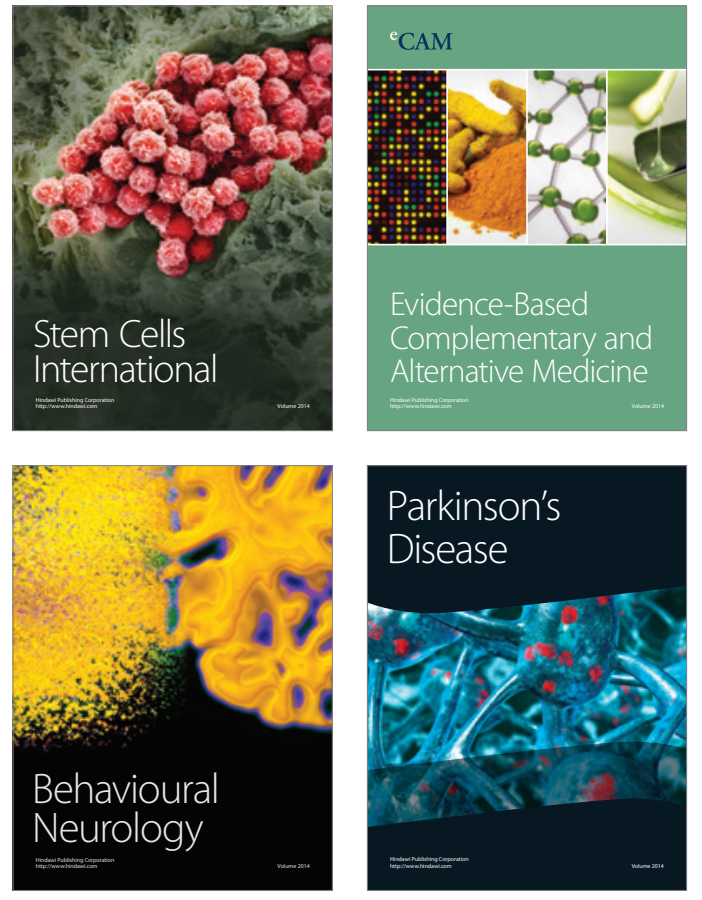
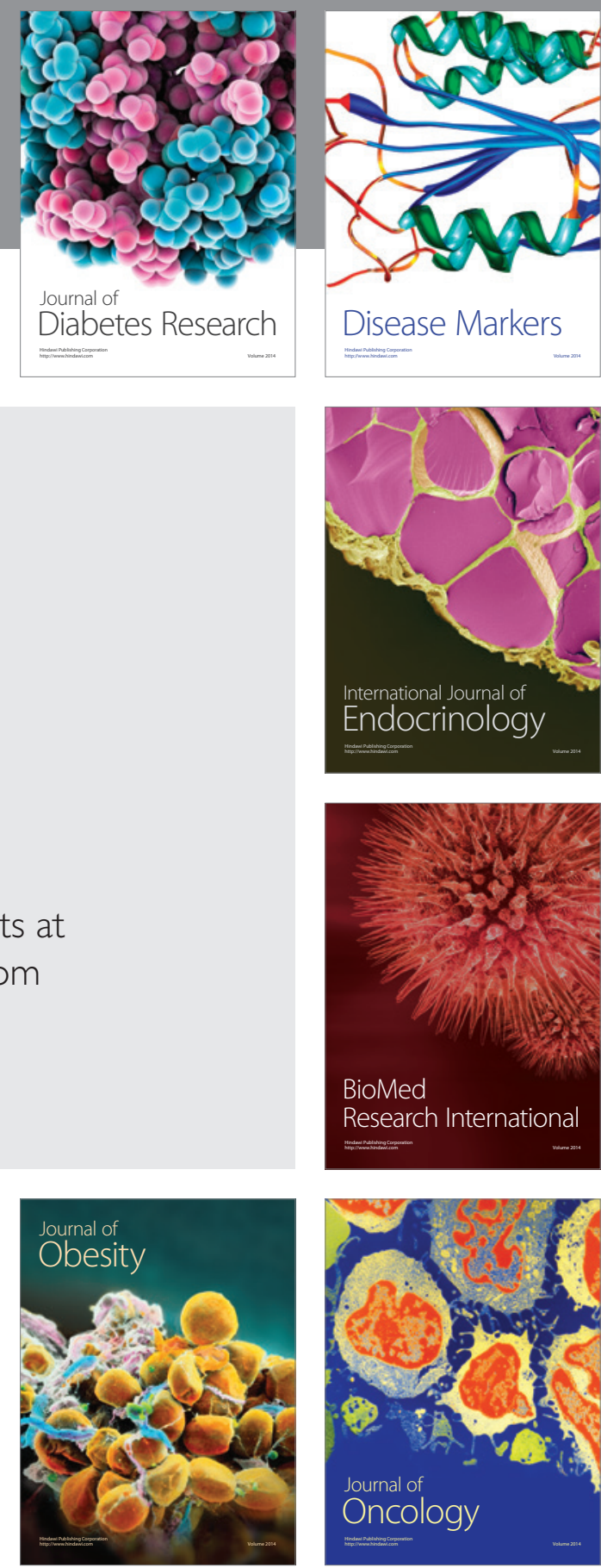

Disease Markers
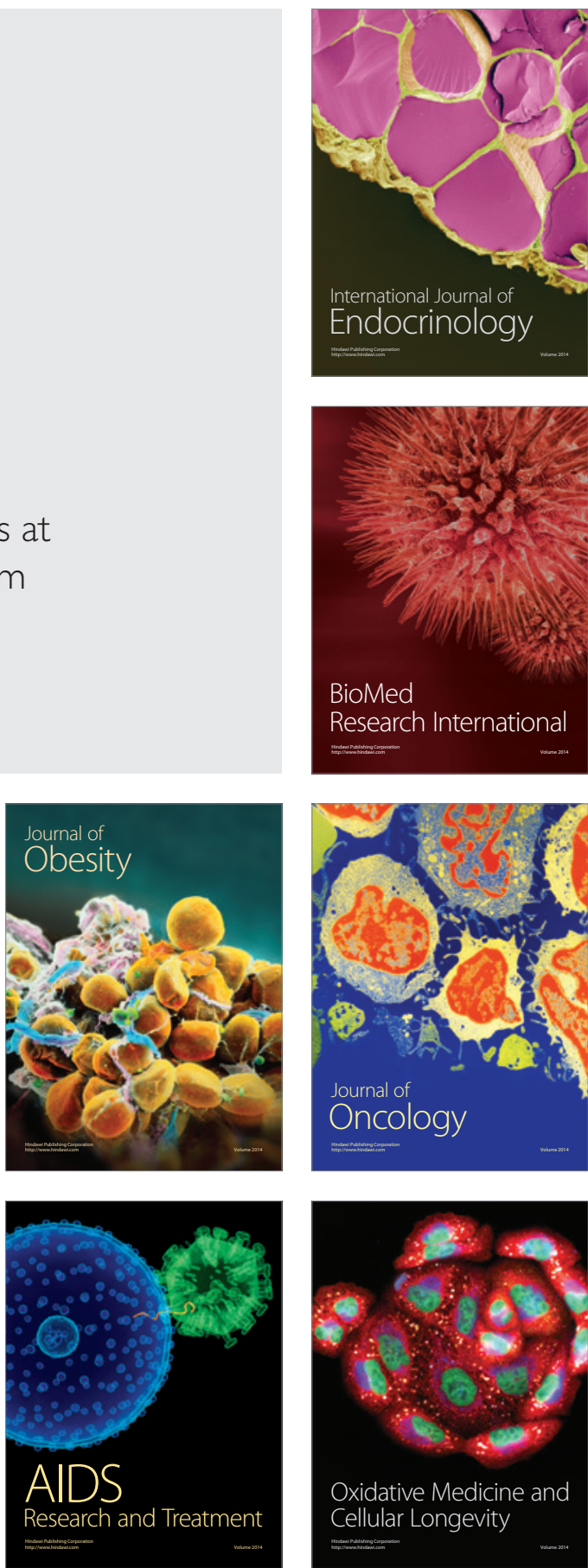